\title{
Diet-dependent rumen epithelial NHE1 and NHE3 expression in sheep
}

\author{
Rasha S. Ahmed ${ }^{1}$, Holger Martens ${ }^{2}$, Christoph Muelling ${ }^{3}$ \\ ${ }^{1}$ Department of Anatomy, Faculty of Veterinary Medicine, P.O. Box 32, University of Khartoum, Sudan, Cell Phone 00249916289454 \\ ${ }^{2}$ Institut of Physiology, Faculty of Veterinary Medicine (WE02), Oertzenweg 19b, Hs. 11 Raum 1.49, Haus B (rechts) 1. Stock 14163 Berlin \\ ${ }^{3}$ Institut of Anatomy, Faculty of Veterinary Medicine, An den Tierkliniken 43,D-04103 Leipzig, Germany
}

Email address:

umraghd72@yahoo.com (R. S. Ahmed), holger.martens@ fu-berlin.de (H. Martens), c.muelling@ vetmed.uni-leipzig.de (C. Muelling)

\section{To cite this article:}

Rasha S. Ahmed, Holger Martens, Christoph Muelling. Diet-Dependent Rumen Epithelial NHE1 and NHE3 Expression in Sheep. Animal and Veterinary Sciences. Vol. 2, No. 6, 2014, pp. 208-212. doi: 10.11648/j.avs.20140206.18

\begin{abstract}
The objective of this study was to characterize the immunohistochemical localization of $\mathrm{Na}^{+} / \mathrm{H}^{+}$exchanger isoforms (NHE1 and NHE3) in the rumen epithelium of Sheep after changing the diet from hay (ad libitum) to a mixed hay/concentrate diet. A total of 24 sheep were fed mixed hay/concentrate for different periods ranging from 0 weeks (control; hay ad libitum) to 12 weeks (1-1.5 kg hay plus $780 \mathrm{~g}$ concentrate per day in two equal portions). NHE3-immunostaining was found to be more intense at both stratum granulosum (deep layer) and stratum spinosum (superficial layer), with decreasing intensity through stratum spinosum (deep or suprabasal layer) and stratum basal. Stratum corneum was negative. Distribution of NHE3 isoform was different within the different strata. In stratum granulosum and stratum spinosum (superficial layer), NHE3 isoform was distributed predominant at the apical surface /membrane of the cells. Meanwhile, in both stratum spinosum (deep layer) and stratum basale, intracellular NHE3 isoform was predominantly. The degree of antibody reaction was weak in hay-fed sheep and in all concentrate-fed groups, except in 2 and 4 weeks concentrate-fed groups, in which the degree of the antibody reaction was moderate and strong, respectively. NHE1 isoform was not detected in the sheep-rumen epithelium.
\end{abstract}

Keywords: Sheep, Rumen Epithelium, NHE1, NHE3, Feed

\section{Introduction}

$\mathrm{Na}^{+} / \mathrm{H}^{+}$exchanger (NHE) of mammalian cells are plasma membrane intrinsic proteins mediating exchange of $\mathrm{Na}$ and $\mathrm{H}$ ions in various tissues. The NHE catalyzes the electroneutral transport of extracellular $\mathrm{Na}^{+}$for intracellular $\mathrm{H}^{+}$. They play a major role in regulation of intracellular $\mathrm{pH}$ (pHi) in addition to transcellular absorption of $\mathrm{Na}^{+}$, cell volume regulation, cell proliferation, adhesion, shape determination and migration (Grinstein et al., 1988; Yun et al., 1995a; Lang et al., 1998; Putney et al., 2002). Nine NHE isoforms have been cloned so far (Yun et al., 1995b; Noel and Pouyssegur, 1995; Ritter et al., 2001; Masereel et al., 2003; Goyal et al., 2003; de Silva et al., 2003). In the gastrointestinal (GI) tract of multiple species, there are resident plasma membrane isoforms including NHE1 (basolateral) and NHE2 (apical), recycling isoforms (NHE3), as well as interacellular isoforms (NHE6, 7, 9). There are many physiological evidences that support the existence of NHE in the rumen. On the other hand, RT-PCR demonstrates expression of multiple NHE family members in the rumen tissue, including NHE1, NHE2, NHE3, and NHE8 (Graham et al., 2007). Immunostaining showed that NHE1 was predominantly localized to the stratum granulosum, with a progressive decrease toward the stratum basale. Meanwhile the study did not mention the localization of NHE3 (Graham et al., 2007).

The primary purpose of the present study was to investigate the effect of the different intervals of concentrates feeding on the expression of NHE1 and NHE3 in adult sheep rumen epithelium and to correlate the cell-specific expression of NHE1 and NHE3 protein with the specific cell types comprising the rumen epithelium.

\section{Materials and Methods}

\subsection{Experimental Animal}

A total of 24 of German dairy sheep of different sex were used in this study. Animals were 9-10 months old at the time of the experiment, and their weights ranged between 33.5-50 
$\mathrm{kg}$. The animals were divided into 8 groups of three animals in each group.

\subsection{Feedings}

Prior to the experiment the sheep were fed only hay ad libitum for at least 8 weeks, in order to adapt them to a lowenergy food. Thereafter, the sheep were either solely fed hay (1-1.5 kg hay/day) (control-group) or received, in addition to that, $780 \mathrm{~g}$ concentrate (experimental-groups). The experimental animals were assigned to 7 groups according to the duration of concentrate feeding: 2, 4 days, 1, 2, 4, 6 and 12 weeks. Introduction of concentrate diet was preceded by an adaptation period of 4 days in which the concentrate feed was increased gradually. The concentrate diet was supplied in equal portions at 07.00 am and $02.30 \mathrm{pm}$. All animals had free access to tap water and salt block.

\subsection{Compositions of Diet}

The nutrient content of both concentrate and hay rations were shown in tables 1 and 2 , respectively.

Tab. 1. Composition of the concentrate diet

\begin{tabular}{llll}
\hline Nutrients & $\%$ & Nutrients & $\%$ \\
\hline Dry matter & 89.1 & Organic ADF & 13.28 \\
Crude ash & 6.42 & Organic NDF & 25.46 \\
Crude protein & 18.03 & ADL & 3.99 \\
Crude fiber & 9.65 & Vitamin A & $7200 \mathrm{Iu}$ \\
Calcium & 0.65 & Vitamin D3 & $1800 \mathrm{Iu}$ \\
Phosphorus & 0.59 & Selenium & $0.5 \mathrm{mg}$ \\
Magnesium & 0.27 & Copper & $10 \mathrm{mg}$ \\
Potassium & 1.35 & DCAB & $+299 \mathrm{meq} / \mathrm{kg} \mathrm{DM}$ \\
Sodium & 0.42 & Net energy lactation (NEL) & $6.7 \mathrm{MJ} / \mathrm{kg}$ \\
Chloride & 0.46 & Metabolic energy (ME) & $10.41 \mathrm{MJ} / \mathrm{kg}$ \\
Sulfur & 0.21 & & \\
\hline
\end{tabular}

Tab. 2. Composition of hay diet

\begin{tabular}{llll}
\hline Nutrients & $\%$ & Nutrients & $\%$ \\
\hline Dry matter & 93.5 & ADL & 4 \\
Crude ash & 4.9 & Non fibers carbohydrates (NFC) & 22.5 \\
Crude protein & 8.8 & Metabolizable energy (ME) & $9.3 \mathrm{MJ} / \mathrm{Kg}$ \\
Crude fiber & 29.3 & Net energy lactation (NEL) & $5.5 \mathrm{MJ} / \mathrm{Kg}$ \\
Potassium & 1.44 & Usable crude protein (nXP) & $120.3 \mathrm{~g} / \mathrm{Kg}$ \\
Sodium & 0.032 & Degradable crude protein (UDP) & $17.6 \mathrm{~g} / \mathrm{Kg}$ \\
Organic ADF & 34 & Ruminal nitrogen balance (RNB) & $-5.2 \mathrm{~g} / \mathrm{Kg}$ \\
Organic NDF & 56.5 & & \\
\hline
\end{tabular}

\subsection{Tissue Collection and Preparation}

Tab. 3. Composition of the transport buffer

\begin{tabular}{ll}
\hline Compound & Concentration $(\mathbf{m m o l} / \mathbf{L})$ \\
\hline Sodium & 145.2 \\
Potassium & 5 \\
Calcium & 1 \\
Magnesium & 1 \\
Bicarbonate & 25 \\
Chloride & 120 \\
Dihydrogenphosphate & 0.4 \\
Hydrogenphosphate & 2.4 \\
Glucose & 5 \\
pH value & 7.4 \\
Osmolarity & $300 \mathrm{mosmol} / \mathrm{L}$ \\
\hline
\end{tabular}

Following the feeding trial and at the end of each experimental period, Full thickness mucosa or rumen papillae isolated directly with scissors from identical site of the rumen (left wall of the recessus ruminis ventral sac; adjacent to the left longitudinal groove) (Gäbel et al, 1987). The ruminal mucosa was cleaned by immersion in a transportation buffer solution (see table 3). Fresh rumenmucosal tissues were fixed in $4 \%$ formalin solution for 24 hours (Romeis, 1989). After rinsing with water, samples were stored in $0.1 \mathrm{mmol} / \mathrm{L}$ phosphate buffer ( $\mathrm{pH}$ 7.2). They were then dehydrated in graded series of ethanol alcohol, cleared with xyline, saturated with and embedded in paraffin. Tissue blocks were then cut at 5-7 $\mu \mathrm{m}$ thickness and collected on microscope slides precoated with Silane solution. Tissues were deparaffinized, hydrated, rinsed twice with distilled water before immunostaining.

\subsection{Antibodies}

\subsubsection{Primary Antibody}

Rabbit $\mathrm{Na}^{+} / \mathrm{H}^{+}$exchanger-3 (NHE3) polyclonal antibody (Fa.Chemicon, USA and Canada) Catalog Nr.AB 3085(incubation with antibodies was done in a humid chambers). This antibody was not tested immunohistochemically before, so there is no any recommended dilution.

\subsubsection{Secondary Antibody}

Peroxidase labelled polymer conjugated to goat anti-rabbit immunoglobulins in Tris-HCl buffer containing carrier protein and an anti-microbial agent, Code N0. K0492 (Fa DakoCytomation, Carpinteria, USA) at room temperature.

\subsubsection{Negative Controls}

The specificity of the staining reaction was determined in control experiments. These comprised either normal mouse or rabbit control serum 1:200 (negative control Ig GI Cat, No. X0931, Fa DakoCytomation, Carpinteria, USA), or omission of the primary antibody; in all cases, sections were negative.

\subsubsection{Procedure of Immunohistochemistry}

For immunolabeling of Hydrogen-Exchanger type 1 and 3 (NHE1, NHE3), both frozen and deparaffinized sections were stained according to the protocol Dako Envision+System, Peroxidase (DAB) (Fa DakoCytomation, Carpinteria / USA). NHE3 was detected in deparaffinized sections. Although both frozen and deparaffinized sections in different antibody-dilutions have been used, NHE1 was not detected. All immunohistochemistry was repeated for material obtained three animals and examined directly under a light microscope (Leica DM LB, Leica Microsystems, Wetzlar, Germany).

Tissues were deparaffinized, hydrated, rinsed twice with distilled water for $5 \mathrm{~min}$ each, washed twice in PBS (PBSPuffer to Dulbecco Cat. No.47302 , Fa. Serva, Heidelberg, Deutschland) for $5 \mathrm{~min}$ each. Dewaxed and rehydrated sections were subjected to inactivation of endogenous peroxidases by an incubation at room temperature in $0.03 \%$ hydrogen peroxide containing sodium azide for 5 minutes. 
Then, the sections were rinsed twice with distilled water for 3 min each, washed in PBS for $10 \mathrm{~min}$. The sections were incubated either with the primary antibody at dilutions of 1:100 in PBS buffer or with control serum at dilutions of 1:200 (control experiments) for $30 \mathrm{~min}$ in a humidified chamber. The sections were washed three times in PBS (twice for $3 \mathrm{~min}$ each and once for $10 \mathrm{~min}$ ). Then, sections were incubated with the secondary antibody for $35 \mathrm{~min}$ at room temperature. The sections were washed three times in PBS (twice for $3 \mathrm{~min}$ each and once for $10 \mathrm{~min}$ ), and color was developed by incubation with $\mathrm{DAB}+$ Chromogensubstrate solution ( $1 \mathrm{ml}$ of buffered substrate solution, $\mathrm{pH} 7.5$, containing hydrogen peroxide and a preservative + one drop of 3, 3-Diaminobenzidin Chromogen solution) for 5-10 min. Sections were rinsed twice with ice cold- distilled water for 5 min each. Then, sections were counterstained with Mayer's Haematoxylin for $5 \mathrm{~min}$, rinsed in distilled water and washed with running tap water for $5 \mathrm{~min}$. Then sections were dehydrated through $70 \%$ ethanol alcohol for $5 \mathrm{~min}$ and $100 \%$ ethanol alcohol three times for $5 \mathrm{~min}$ each, cleared three times in xyline for $5 \mathrm{~min}$ each, and mounted with Canada balsam permanent mounting media (Sigma-Aldrich).

\section{Results}

NHE1 isoform was not detected in the sheep-rumen epithelium. NHE3 transporter protein isoform was localized at both apical plasma membrane (more dense) and intracellular locations (Table. 4; Fig.1). NHE3 was found to be more intense at both stratum granulosum and stratum spinosum (superficial layer adjacent to stratum granulosum), with decreasing intensity through stratum spinosum (deep or suprabasal layer) and stratum basale. Stratum corneum was negative (Fig.1). Distribution of NHE3 isoform was different within the different strata. In stratum granulosum, NHE3 isoform was presented at apical and basolateral cell membrane. In stratum spinosum (superficial layer), NHE3 isoform was distributed predominant at the apical surface /membrane of the cells. Meanwhile, in both stratum spinosum (deep layer) and stratum basale, the expression of the intracellular NHE3 isoform was predominant (Fig. 1).

Table 4. The effect of type and duration of concentrate feeding on the expression of NHE3 at different strata of the rumen epithelium. $(N=3$ animals for each treatment)

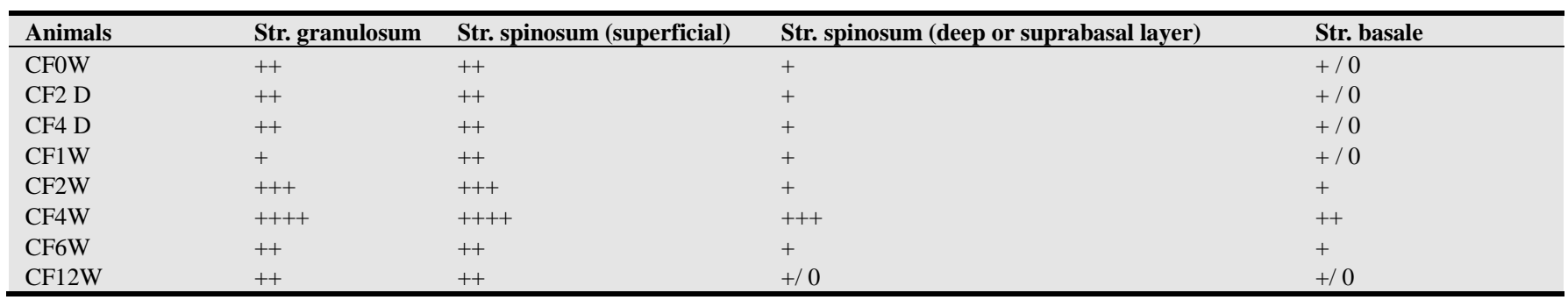

$0=$ no reaction $+=$ very weak $++=$ weak $+++=$ moderate $++++=$ strong

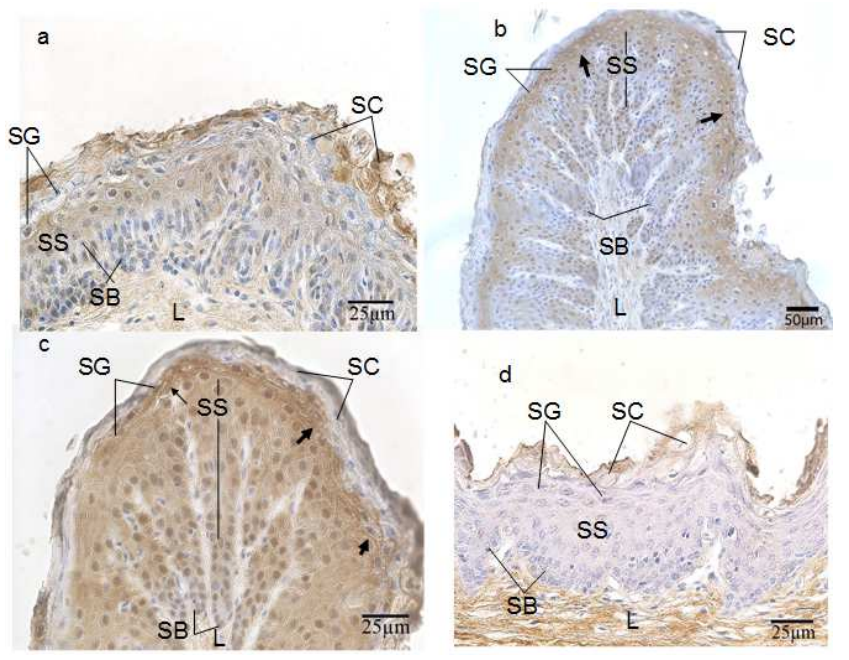

Fig. 1. Micrographs of the ruminal epithelium showing different immunoreactivity for NHE3 staining among sheep groups a. Hay-fed group (weak-reaction) b. 2 weeks concentrate-fed group (moderate-reaction)

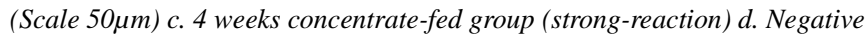
control. Notice: the intense staining of the NHE3 at both deep layer of stratum granulosum (SG) and superficial layer of stratum spinosum (SS), with decreasing intensity through the suprabasal spiny cells and cells of stratum basale (SB). Stratum corneum (SC) was negative. Arrows $(\rightarrow)$ pointed to the apical staining of the NHE3. L: lamina propria. (Scale 25 $\mathrm{mm}$ )
Immunohistochemical staining for NHE3 in ruminal epithelium showed different degrees of staining among sheep groups (Table. 4). Ruminal epithelium of hay-fed group, 2-4 days and 1 week concentrate-fed groups showed weak antibody reactions. Positive NHE3-immunostaining was observed at granular cells and superficial spiny cells (apical surface) and decreased in intensity through stratum spinosum (suprabasal layer) to stratum basale (Fig. 1). Ruminal epithelium from 2 weeks concentrate-fed group showed moderate antibody reaction. Ruminal epithelium from 4 weeks concentrate-fed group, showed strong antibody reaction compared to the previous mentioned groups (Fig. 1). The intense staining included all strata of the epithelium except stratum corneum. It was more intense at granular cells (at apical and basolateral membrane) and superficial spiny cells (at apical surface). Some basal cells showed apical staining for NHE3 isoform. Ruminal epithelium from 6 or 12 weeks concentrate-fed groups, showed weak and very weak antibody reactions, respectively (Table. 4). Weak local reaction for NHE3 isoform was seen at both stratum granulosum and stratum spinosum (superficial layer adjacent to stratum granulosum), with decreasing intensity throughout stratum spinosum (suprabasal layer) and stratum basale. 


\section{Disscusion}

Feeding concentrate diet leads to excessive production of SCFA and as a consequence of the transport of these products the intracellular $\mathrm{pH}$ (pHi) could be sharply reduced. Therefore, an efficient $\mathrm{pH}$ regulatory mechanism(s) is required to keep the intracellular $\mathrm{pH}$ within the physiological value; one of these mechanisms could be mediated by NHE (Graham et al., 2007). Schweigel et al. (2005) demonstrated the presence of mRNA for both NHE1 and NHE3 in the rumen.

The present findings showed that NHE3-immunostaining exists in almost all strata of the epithelium except stratum corneum, with higher intense expression at both stratum granulosum (deep layer) and stratum spinosum (superficial layer) ; predominantly at the apical surface of the cells. This is in consistent with many previous studies in other tissues, which reported the localization of NHE3 to be restricted to the apical membrane (Hoogerwerf et al., 1996; Biemesderfer et al., 1997). Because the stratum corneum is a dead layer, it showed negative reaction for this isoform.

Nevertheless, the degree of antibody reaction was weak in hay fed-sheep and in all concentrate-fed groups, with exception of 2 and 4 weeks concentrate-fed groups, in which the degree of the antibody reaction was moderate and strong, respectively. Transepithelial $\mathrm{Na}$ transport is only mediated by apical uptake via NHE3 in connection with extrusion of Na by the basolaterally located Na-K-ATPase (Rabbani et al., 2011). Moreover, the trafficking capability of NHE3 from the intracellular vesicles to the plasma membrane in response to challenge caused by reduction in the intracellular $\mathrm{pH}$ is well known (Kurashima et al. 1998; Chow et al. 1999). Furthermore, the enhancement of $\mathrm{Na}$ transport across the ruminal epithelia due to the presence of SCFA has been also reported, probably takes place by NHE (Gäbel et al. 1991; Sehested et al. 1996). SCFA, in particularly butyrate, induces NHE3 activity and its protein and mRNA expression both in vivo and in vitro (Kiela et al., 2007). Therefore, the increase in the expression of NHE3 with increasing the duration of feeding concentrate could be due to the high concentration of SCFA. On the other hand, the time course of functional rumen epithelium adaptation after a change from hay feeding ( $\mathrm{ad}$ libitum) to a mixed hay/concentrate diet was monitored by measuring $\mathrm{Na}^{+}$transport rates in Ussing chamber experiments (Etschmann et al., 2009). According to these authors, the net $\mathrm{Na}$ transport significantly rose after one week of mixed hay/concentrate diet, reached peak levels after four weeks and levelled out after 12 weeks of mixed feeding. The transport capacity of the ruminal epithelia could reach its maximum and the continuous accumulation of SCFA could increase the osmolarity of the ruminal contents. Wakabayashi et al. (1997) found that NHE3 activity is decreased by the hyperosmolarity. Since, the hyperosmolarity decreases intracellular $\mathrm{pH}$ and inhibits $\mathrm{Na}$ transport in the rumen, probably by inhibition of NHE3 (Schweigel et al., 2005), the weak antibody reaction observed in 6 and 12 weeks concentrate-fed animal can be justified in this context. The delay in response to feeding concentrate until 1 week (low antibody reaction against NHE3) could show that the expression of this isoform may require this period to be strongly expressed. This study is the first one which identifies NHE3 in the rumen using immunohistochemistry technique.

\section{References}

[1] Biemesderfer, D.; Rutherford, P. A.; Nagy, T.; Pizzonia, J. H.; Abu-Alfa, A. K. and Aronson, P. S. (1997) Monoclonal antibodies for high-resolution localization of NHE3 in adult and neonatal rat kidney. Am. J. Physiol. 273: F289-F299

[2] Chow, C. W.; Khurana, S.; Woodside, M.; Grinstein, S. and Orlowski, J. (1999) The epithelial $\mathrm{Na}+\mathrm{H}+$ exchanger, NHE3, is internalized through a clathrin-mediated pathway.J. Biol. Chem. 274: 37551-37558

[3] De Silva, M. G.; Elliott, K.; Dahl, H. H.; Fitzpatrick, E. and Wilcox, S. (2003) Disruption of a novel member of a NHE family and DOCK3 is associated with an attention deficit hyperactivity disorder-like phenotype. J. Med. Genet. 40: 733740 .

[4] Etschmann, B, Suplie, A and Martens, H (2009): Change of ruminal sodium transport in sheep during dietary adaptation. Archives of Animal Nutrition, 63: 26-38.

[5] Gäbel, G.; Martens, H.; Suendermann, M. and Galfi, P. (1987) The effect of diet, intraruminal $\mathrm{pH}$ and osmolarity on sodium, chloride and magnesium absorption from the temporarily isolated and washed reticulo-rumen of sheep. Q. J. Exp. Physiol. 72: 501-511

[6] Gäbel, G.; Vogler, S. and Martens, H. (1991) Short chain fatty acids and $\mathrm{CO} 2$ as regulators of $\mathrm{Na}+$ and $\mathrm{Cl}$ - absorption in isolated sheep rumen mucosa. J. Comp. Physiol. B, 161: 419426

[7] Goyal, S.; Vanden, H. G. and Aronson, P. S. (2003) Renal expression of novel $\mathrm{Na}+\mathrm{H}+$ exchanger isoform NHE8. Am. J. Physiol. 284: F467-F473

[8] Graham, C.; Gatherar, I.; Haslam, I.; Glanville, M. and Simmons, N. L. (2007) Expression and localization of monocarboxylate transporters and sodium/proton exchangers in bovine rumen epithelium. Am. J. Physiol. Regulatory Integrative Comp. Physiol. 292: 997-1007

[9] Grinstein, S.; Clarke, C. A. and Rothstein, A. (1988) Activation of $\mathrm{Na}+\mathrm{H}+$ exchange in lymphocytes by osmatically induced volume changes and by cytoplasmatic acidification. J. Gen. Physiol. 82: 619-638

[10] Hoogerwerf, W. A.; Tsao, Su. C.; Devuyst, O.; Levine, S. A.; Chris Yun, C. H.; Yip, J. W.; Cohen, M. E.; Wilson, P. D.; Lazenby, A. J.; Tse, C. M. and Donowitz, M. (1996) NHE2 and NHE3 are human and rabbit intestinal brush-border proteins. Am. J. Physiol. 270: G29-G41

[11] Kiela, P. R.; Kuscuoglu, N.; Midura, A. J.; Midura-Kiela, M. T.; Larmonier, C. B.; Lipko, M.; Ghishan, F. K. (2007) Molecular mechanism of Rat NHE3 gene promoter regulation by sodium butyrate. Am. J. Physiol., cell physiol. 293: C64-74

[12] Kurashima, K.; Szabo, E. Z.; Lukacs, G.; Orlowski, J. and Grinstein, S. (1998) Endosomal recycling of the $\mathrm{Na}+\mathrm{H}+$ exchanger NHE3 isoform is regulated by the phosphatidylinositol 3-kinase pathway. J. Biol. Chem. 273: 20828-20836 
[13] Lang, F.; Busch, G. L.; Ritter, M.; Völkl, H.; Waldegger, S.; Gulbins, E. and Häussinger, D. (1998) Functional significance of cell volume regulatory mechanisms. Physiol. Rev. 78: 247306

[14] Masereel, B.; Pochet, L. and Laeckmann, D. (2003) An overview of inhibitors of $\mathrm{Na}+\mathrm{H}+$ exchanger. Eur. J. Med. Chem. 38: 547-554

[15] Noel, J. and Pouyssegur, J. (1995) Hormonal regulation, Pharmacology, and membrane sorting of vertebrate $\mathrm{Na}+\mathrm{H}+$ exchanger isoform. Am. J. Physiol. 268: C 283-C296

[16] Putney, L. K.; Denker, S. P. and Barber, D. L. (2002) The changing face of the $\mathrm{Na}+\mathrm{H}+$ exchanger, NHE1: structure, regulation, and cellular actions. Annu. Rev. Pharmacol. Toxicol. 42: 527-552

[17] Rabbani, I; Siegling-Vlitakis, C; Noci, B; Martens, H. (2011) Evidence for NHE3-mediated $\mathrm{Na}$ transport in sheep and bovine forestomach. Am J Physiol Regul Integr Comp Physiol. 30: 313-319.

[18] Ritter, M.; Fuerst, J.; Woll, E.; Chwatal, S.; Gechwentner, M.; Lang, F. and Paulmichl, M. (2001) Na+/ H+ exchangers; linking osmotic dysequilibrium modified cell function. Cell Physiol. Biochem. 11: 1-18.
[19] Romeis, B. (1989) Mikroskopische Technik. Verlag Urban und Schwarzenberg, München, Wien und Baltimore, 17. Auflage.

[20] Schweigel, M.; Freyer, M.; Leclercq, S.; Etschmann, B.; Lodemann, U.; Bottcher, A. and Martens H. (2005) Luminal hyperosmolarity decreases $\mathrm{Na}$ transport and impairs barrier function of sheep rumen epithelium. J. Comp. Physiology. B, 175: 575-591.

[21] Sehested, J.; Diernaes, I.; Moller, P. D. and Skadhauge, E. (1996) Transport of $\mathrm{Na}$ across the isolated bovine rumen epithelium: Interaction with short-chain fatty acids, chloride and bicarbonate. Exp. Physiol. 81: 79-94.

[22] Wakabayashi, S.; Shigekawa, M. and Pouyssegur, J. (1997) Molecular physiology of vertebrate $\mathrm{Na}+\mathrm{H}+$ exchangers. Physiol. Rev. 77: 51-74.

[23] Yun, C. H.; Tse, C. M.; Nath, S. K.; Levine, S. A.; Brant, S. R. and Donowitz, M. (1995a) Mammalian Na_/H_ exchanger gene family: structure and function studies. Am. J. Physiol. Gastrointest. Liver Physiol. 269: G1-G11

[24] Yun, C.; Tse, C.; Levine, S. and Donowitz, M. (1995b) Structure/function studies of mammalian $\mathrm{Na}+/ \mathrm{H}+$ exchangers - an update. J. Physiol. 482: 1-6. 